\title{
Temperature variations in a housing of the semi-arid region of Djelfa (Algeria)
}

\author{
Fatiha Youcef Ettoumi ${ }^{\mathrm{a}, ~ *}$, Nacer Messen ${ }^{\mathrm{b}}$, Abd-El-Hamid Adane ${ }^{\mathrm{a}}$, Henri Sauvageot ${ }^{\mathrm{c}}$ \\ a Université de Sciences et Technologie Houari Boumediène (U.S.T.H.B.), Faculté de Génie Electrique, Laboratoire Traitement d'Images et \\ Rayonnement, B.P. 32 El Alia, Bab Ezzouar, Alger, Algeria \\ ${ }^{\mathrm{b}}$ C.N.R.B.-BP. 212 Ain Oussera, Wilaya de Djelfa, Algeria \\ ${ }^{\mathrm{c}}$ Université Paul Sabatier, Observatoire Midi Pyrénées, Laboratoire d'Aérologie, 14 avenue Edouard Belin, 31400, Toulouse, France
}

\begin{abstract}
Temperature variations are analysed for two areas of Algeria, lying in a semi-arid region and near the West Coast, respectively, the Djelfa and Oran areas. This analysis mainly consists in computing the temperature deviations with respect to the reference levels of $18^{\circ} \mathrm{C}$ and $25^{\circ} \mathrm{C}$. Their time variations are then studied. When summing the temperature deviations per month, the amount of energy, expressed in degree hour for each month of the year, necessary to heat and cool the houses during cold weather and hot periods, respectively, is obtained. An economic study of construction material efficiency is associated with the computation of the temperature deviations and applied to housing in semi-arid regions. It is shown that cheap traditional materials having great thermal inertia can advantageously be used for housing constructions in these regions.
\end{abstract}

Keywords: Building insulation; Vernacular architecture; Ambient temperature; Thermal deviation; Semi-arid region; Home comfort; Heating; Air-conditioning

\section{Introduction}

In semi-arid regions, weather is very cold in winter and hot in summer. In addition, temperature varies strongly from day to night $[1-10]$. In such conditions, the houses of these regions are subjected to important temperature variations. These dwellings must then be thermally insulated and designed to insure some comfort for people living in them.

The concept of comfort depends on various factors, mainly external temperature, hygrometric degree and wind $[11,12]$. It is also a function of ambient temperature, amount of energy brought by solar radiation, terrestrial environment and clothing effect [13-15].

The present study only deals with the effect of air temperature on housing because this parameter is pivotal in the calculation of the air-conditioning and heating systems. In general, comfort temperature is the temperature at which human can live harmoniously $[16,17]$. According to previous

\footnotetext{
* Corresponding author. Université Paul Sabatier, Observatoire Midi Pyrénées, Laboratoire d'Aérologie, CRA, 65300 Lannemezan, France. Tel.: +33-56-24-40-61-15; fax: +33-5-62-40-61-01.

E-mail address: youcefettoumi@yahoo.fr (F. Youcef Ettoumi).
}

studies published in the literature, the climate prevailing in semi-arid regions can be described as having only two main seasons, namely winter and summer. These seasons can be characterised by two types of comfort temperatures. The thermal deviations measured with respect to each comfort temperature play an important role in the design of housing. The number of degree hour necessary to either heat or cool a house in a semi-arid region can, therefore, be computed by knowing the times series of these deviations.

In order to discuss the possibility of minimising energy consumption due to heating and cooling, this calculation must be completed by evaluating an index quantifying the protection efficiency of buildings against external temperature variation from the annual thermal extremes observed in the region under consideration. Dwellings must be designed to possess a great thermal inertia [18-20]. In practice, this means that the construction materials must be chosen so that the lifetime of these dwellings is increased and energy losses are reduced.

In Algeria, the building standard presently adopted in the high plateau of Atlas, is the same as in the coastal plain of the northern part of the country. In southern Algeria, houses are usually divided into two life centres. One is used in summer, 
and the other in winter. This organisation aims at getting a better climatic adaptation and an efficient protection of the houses against heat excess in summer. In the rest of the country, only aspects such as house orientation in connection with the incidence angle of the solar rays, the size and shape of the openings or type of ventilation, are considered in the architecture of the houses.

In spite of these precautions, thermal insulation represents about $10 \%$ of the cost of construction. In fact, the temperature effects on housing are ignored by the architects and buildings contractors, because of the cost of the thermal insulation. They are only considered in the case of prestige constructions. However, to get the best conditions of energy exchanges and to respect the environment, the effect of temperature variations and the features of construction materials must be taken into account in the design of the housing.

The analysis presented hereafter is based on the processing of hourly temperature data collected by two meteorological data acquisition systems situated in a semi-arid region and a coastal one, i.e. the regions of Djelfa and Oran, respectively. The results obtained in both regions are compared.

\section{Data}

The data collection system assigned to the characterisation of semi-arid regions, is an automatic station equipped with various meteorological sensors. This station is situated in a steppic region of the high plateau of Atlas, limited by mountain ranges in the south and north. It is set installed in the site of Benahar, $8 \mathrm{~km}$ south of Birine, near Djelfa (Ain Oussera), on a flat sandy area. The yearly cumulative precipitation amount lies between 100 and $250 \mathrm{~mm}$ [21]. Temperatures were measured with a $100 \Omega$ platen resistance thermometer placed in a small shelter. This sensor can measure temperature from $-40^{\circ} \mathrm{C}$ to $+60^{\circ} \mathrm{C}$, with a resolution of $0.1^{\circ} \mathrm{C}$. The minimum, maximum and mean temperature values are scanned and recorded automatically every $10 \mathrm{~min}$ by the station. Similar measurements were performed in the meteorological station of Oued Tlilat, situated in the plain, about $40 \mathrm{~km}$ east of Oran. This region is influenced by the proximity of the Mediterranean sea [22]. Hence, the climate prevailing in the region is both wet and temperate. For the two sites under consideration, the experimentation began on 1 April 1999 and ended on 1 April 2000, which means that temperature measurements have been collected for $1 \mathrm{yr}$.

\section{Methodology}

After investigations on the welfare of populations, the comfort temperature has been fixed at $18^{\circ} \mathrm{C}$ in winter and $25^{\circ} \mathrm{C}$ in summer. Taking into account these empirical thresholds, the set of instantaneous temperature deviations, with respect to the comfort temperatures, for a given location and period are considered. Next, the deviations, with respect to the thresholds, observed every hour, are added. The sum of these deviations is then expressed in degree hour. A degree hour (DH) is the equivalent of an instantaneous temperature deviation of one degree observed over an interval of time of one hour. Consider a month having $n$ days, and let $T(h, d)$ be the hourly ambient temperature mean, in Celsius degrees, measured at hour $(h)$ on day $(d)$. If $T(h, d)$ is below $18^{\circ} \mathrm{C}$, the dwellings of the region under consideration must be heated. In this case, the number of degree hour involved in the heating (that is the sum of temperature deviations) is simply:

$\sum_{\text {heat }} \mathrm{DH}=\sum_{d=1}^{n} \sum_{h=1}^{24}[18-T(h, d)] K_{18}(T(h, d))$,

where $n$ is the number of day of the month.

In this expression, the heating hours are totalled by using a function defined as

$K_{18}(T(h, d))=1 \quad$ if $T(h, d)<18^{\circ} \mathrm{C}$,

$K_{18}(T(h, d))=0 \quad$ if $T(h, d) \geqslant 18^{\circ} \mathrm{C}$.

The number of hours involved in the heating during the month is

$\sum_{\text {heat }} H=\sum_{\text {heat }} K_{18}(T(h, d))$.

The sum $\left(\sum_{\text {heat }} \mathrm{DH}\right)$ is calculated for each month of the year and expressed in degree hour. It enables the evaluation of the heating needs of a house situated in a semi-arid region.

Similarly, when weather is hot, houses must be cooled by means of air-conditioning. The number of degree hour involved in the cooling of a house during one month, is given by

$\sum_{\text {cool }} \mathrm{DH}=\sum_{d=1}^{n} \sum_{h=1}^{24}[T(h, d)-25] K_{25}(T(h, d))$.

In the case of cooling, the function is written as

$K_{25}(T(h, d))=1 \quad$ if $T(h, d)>25^{\circ} \mathrm{C}$,

$K_{25}(T(h, d))=0 \quad$ if $T(h, d) \leqslant 25^{\circ} \mathrm{C}$.

It is found that the number of hours involved in the cooling per month is

$\sum_{\text {cool }} H=\sum_{\text {cool }} K_{25}(T(h, d))$.

Thanks to this approach, energy needed by a dwelling in a semi-arid region can be quickly evaluated, provided that a specific measurements campaign is performed in the region and the thermal inertia characterising the house is known. In general, thermal inertia expresses the ability of construction materials to work as thermal insulators. According to the 
different sorts of constructions, four classes of thermal inertia can be distinguished. They are referred as:

- weak thermal inertia (in the case of huts)

- small thermal inertia (corresponding to rooms made of light walls and floors)

- mean thermal inertia (characterising rooms consisting of heavy walls and floors)

- strong thermal inertia (constructions made of double heavy walls and floors, but without internal thermal insulation).

In the region of Djelfa, temperature varies widely with time. Then, the houses of this region must be built with construction materials having strong thermal inertia. The design of such houses requires the computation of the maximum amplitude of the daily thermal deviations $\Delta T(d, m)$, monthly extremes of $\Delta T(d, m)$, yearly extremes and the maximum deviation of yearly extremes. The minimum and maximum daily temperatures are called $T_{\mathrm{Min}}(h, d)$ and $T_{\text {Max }}(h, d)$, respectively. On day $(d)$ of month $(m)$, the maximum daily thermal deviation is defined as

$\Delta T(d, m)=T_{\mathrm{Max}}(h, d)-T_{\mathrm{Min}}(h, d)$

with $d=1, \ldots, n$.

The maximum amplitude of the monthly thermal deviation $\Delta T(m)_{\text {Max }}$ for a month $(m)$ is

$\Delta T(m)_{\operatorname{Max}}=\Delta T(d, m)_{\operatorname{Max}}$,

with $m=1, \ldots, 12$.

The maximum difference between the monthly deviation is

$\Delta T(y)_{\operatorname{Max}}=\Delta T(m)_{\operatorname{Max}}-\Delta T(m)_{\operatorname{Min}}$,

where $\Delta T(m)_{\text {Min }}$ is the minimum monthly thermal deviation, and $\Delta T(m)_{\text {Max }}$ is the maximum monthly thermal deviation as respectively observed.

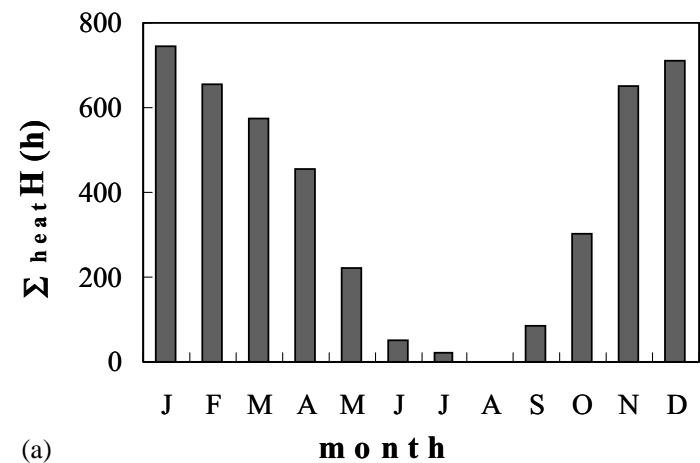

\section{Heating and cooling needs}

The duration and number of degree hour required for either heating or cooling in both locations under study, have been calculated for each month of the year, following the method presented in Section 3. The plots of Fig. 1 give the number of hours of heating and the temperature deviations $\left({ }^{\circ} \mathrm{C} \mathrm{h}\right.$ ) with respect to $18^{\circ} \mathrm{C}$, obtained in Benahar, for each month of the year.

These plots indicate that the constructions in Benahar must be continuously heated in January and December, with more than 10,000 and 9000 degree hour, respectively. The number of degree hour is found to be insignificant in June, July, August, and September. In May and October, this number is equal to only 840 degree hour, which means that houses are seldom heated during these months. For the other months, the number of degree hour lies between 3000 and 10,000. The plots of Fig. 2 represent the monthly temperature deviations $\left({ }^{\circ} \mathrm{Ch}\right)$ with respect to $25^{\circ} \mathrm{C}$ and the related number of hours of cooling in Benahar. Fig. 2 shows that air-conditioning is useless in January, February, March, April, October, November, and December. For the other months, the number of degree hour necessary to cool houses in Benahar, runs from 1000 to $5000^{\circ} \mathrm{C} \mathrm{h}$. For example, $1700^{\circ} \mathrm{C}$ and $1200^{\circ} \mathrm{C} \mathrm{h}$ of cooling are, respectively, needed in May and September, whereas the maximum of degree hour is reached in August, equalling almost $5000^{\circ} \mathrm{C} \mathrm{h}$. In the region of Djelfa, a yearly amount of 42,347 degree hour must be brought to insure 3688 h of heating, whereas 14,833 degree hour have to be evacuated to get $2283 \mathrm{~h}$ of cooling.

In general, air-conditioning and heating installations are expensive. To reduce the cost of comfort in the region of Djelfa, heating and air conditioning in a given house, must be rationally used over the year. The results given in Figs. 1 and 2 must then be taken into account in the design of the constructions, and in the choice of their architecture. This means that the construction materials, air circulation and house orientation have to be properly chosen. Such constructions are submitted to strong temperature variations. The plots of Fig. 3 indicate that the daily thermal deviations for

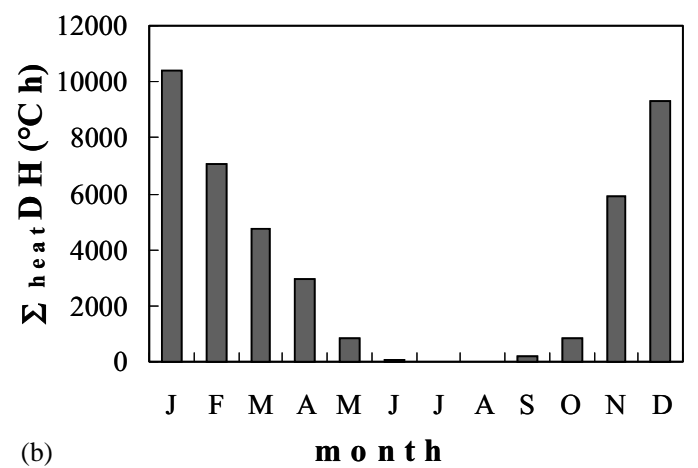

(b)

mont h

Fig. 1. (a) Number of hours of heating $\left(\sum_{\text {heat }} H\right)$ and (b) Number of degree hour of heating with respect to $18^{\circ} \mathrm{C}\left(\sum_{\text {heat }} \mathrm{DH}\right)$ in Benahar $(\mathrm{Djelfa})$. 


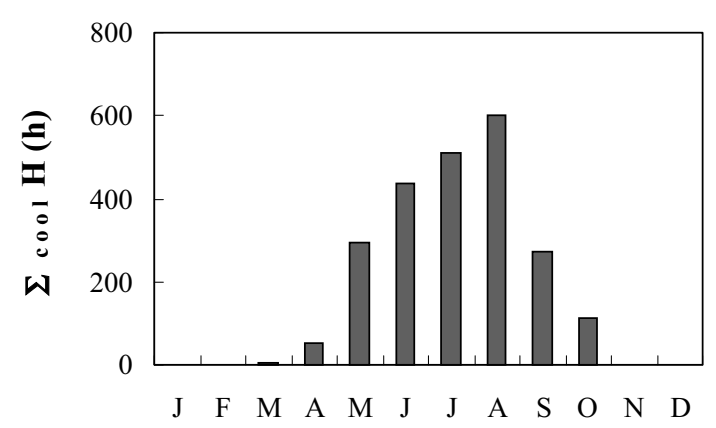

(a)

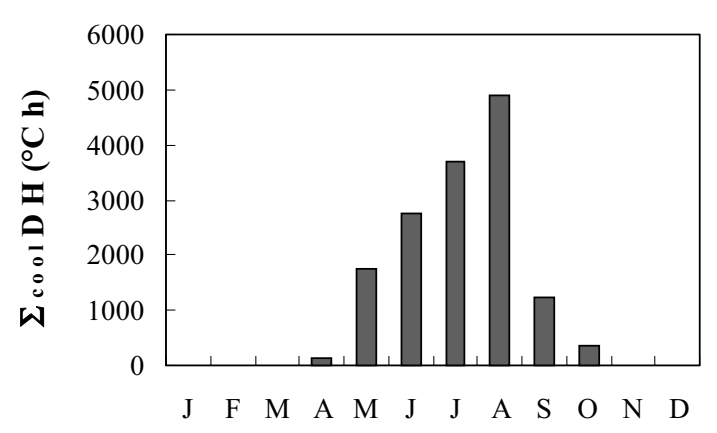

(b)

mo $\mathbf{n}$ t h

Fig. 2. (a) Number of hours of cooling $\left(\sum_{\text {cool }} H\right)$ and (b) Number of degree hour of cooling with respect to $25^{\circ} \mathrm{C}\left(\sum_{\text {cool }} \mathrm{DH}\right)$ in Benahar $(\mathrm{Djelfa})$.
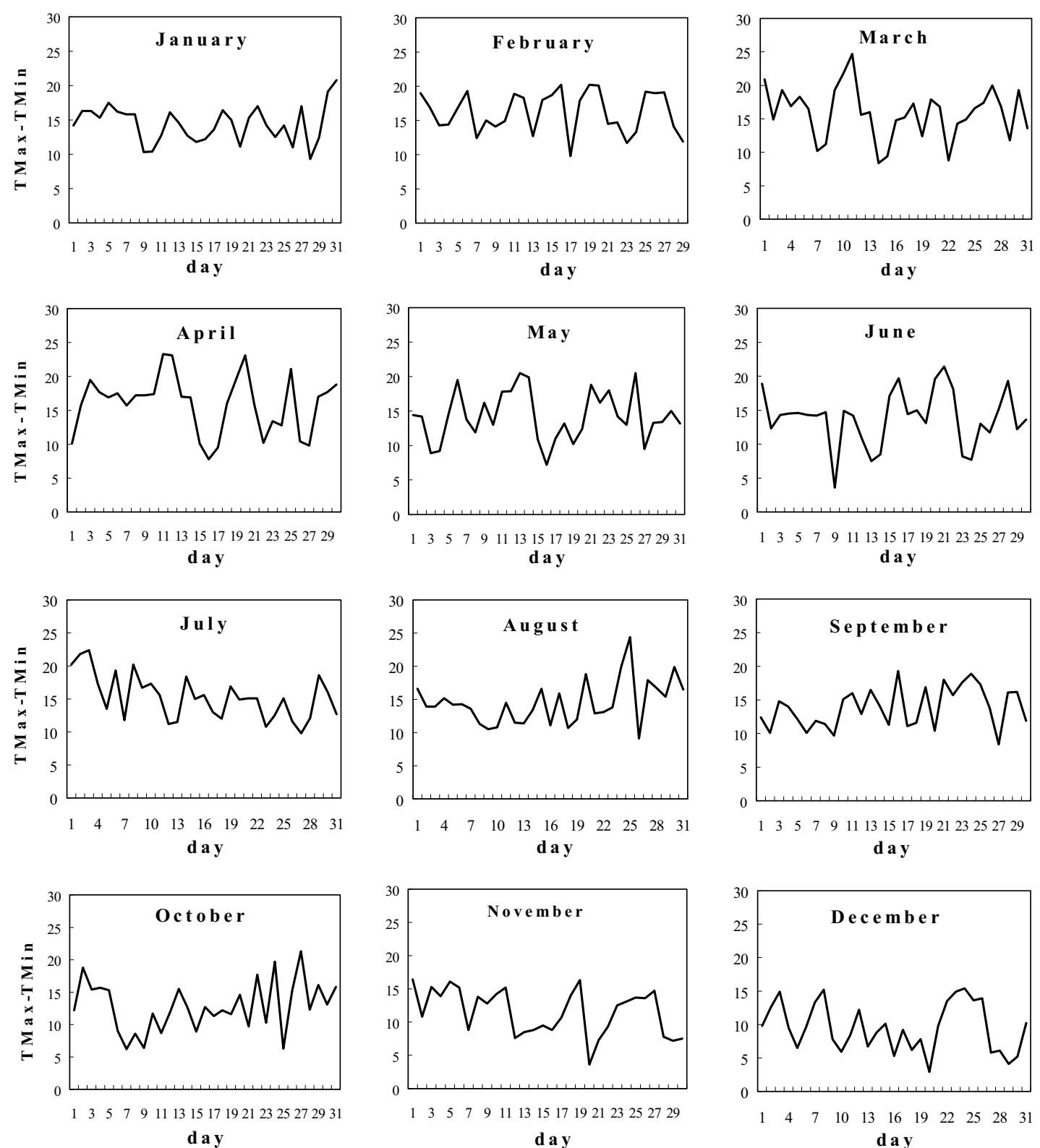

Fig. 3. Daily thermal deviations $\left({ }^{\circ} \mathrm{C}\right)$ observed in Benahar (Djelfa) from January-December. $\left(T_{\text {Max }}=\right.$ maximum temperature and $T_{\text {Min }}=$ minimum temperature). 


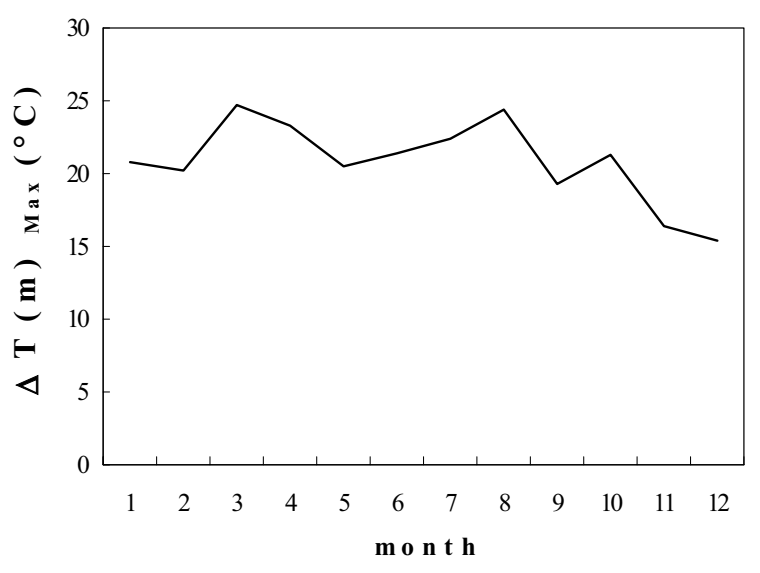

Fig. 4. The maximum amplitude of the monthly thermal deviation, $\Delta T(m)_{\operatorname{Max}}=\operatorname{Max}\left(T_{\mathrm{Max}}(h, d)-T_{\mathrm{Min}}(h, d)\right)$, observed in Benahar (Djelfa).

each month of the year vary significantly from one month to another. For instance, the minimum daily thermal deviations observed in April, July, October, and December are equal to $6.6^{\circ}, 11.7^{\circ}, 7.2^{\circ}$, and $4^{\circ}$, respectively. To account for the heating effect of climate on a given house in Benahar, it is more relevant to consider the maximum monthly thermal deviations than the daily thermal variations. The monthly extremes observed for each month of the year, are given in Fig. 4. The maximum value of monthly extreme $\Delta T(m)_{\text {Max }}$ reaches $25.1^{\circ} \mathrm{C}$ whereas the minimum is $18^{\circ} \mathrm{C}$. Hence, the yearly extreme is $\Delta T(y)_{\operatorname{Max}}=7.1^{\circ} \mathrm{C}$.

Application of the method described in Section 3 to the temperature data collected in the location of Oued Tlilat, gives the plots of Figs. 5-8. The duration and number of degree hour required every month for either heating or cooling at this location, are, respectively, given by the plots of Figs. 5 and 6 . The latter show that heating is necessary in winter, for the period running from November to April and air-conditioning must be employed in summer, from June to September. During the year, 9353 degree hour distributed over $1978 \mathrm{~h}$, must be removed to cool habitations in the plain of Oued Tlilat and their heating requires 24378 degree hour sprayed over $2898 \mathrm{~h}$.

The monthly variations of daily thermal deviations are represented by the plots of Fig. 7. For Benahar, important variations of the daily thermal deviations are observed from one month to another. The monthly extremes calculated from the daily thermal deviations, are plotted in Fig. 8. According to the resulting diagram, the yearly extreme equals $9.3^{\circ} \mathrm{C}$ for this region.

All these results show that the climate in the plain of Oued Tlilat and its temperature variations are very different from those of the region of Djelfa. In addition, the needs of heating and air-conditioning are obviously more important in the semi-arid region than in the temperate ones.

\section{Insulation materials}

Most architects usually estimate the thermal insulation of houses, knowing the yearly thermal extremes of the region under study. Since the yearly thermal extreme values observed for Benahar and Oued Tlilat, are nearly the same, it then seems that the same kind of houses can be constructed in both regions. However, to insure better life conditions in the dwellings of semi-arid regions, the duration of either heating or cooling and the related number of degree hour, must also be included in the calculation of thermal insulation. The construction materials are then chosen according to their thermal inertia, but also by taking into account the economic aspects. The thermal inertia of a given material is measured by its time constant. The latter is calculated by solving the equation of thermal energy exchanges. Considering an homogeneous wall and assuming one dimension heat flow, this equation is written as

$P+k S\left(T_{\mathrm{a}}-T\right)=m C \frac{\mathrm{d} T}{\mathrm{~d} t}$.

In this expression, $P$ is the incident thermal power, $T_{\mathrm{a}}$, the ambient temperature, $T$, the inner temperature, $m$, the mass of the wall, $S$, its surface and $C$, its heat capacity. Let $\lambda$ be the conductivity of the wall and $e$, its thickness. Its thermal resistance is then: $R=e / \lambda$ and the conductance $(k)$ is given by

$\frac{1}{k}=R+\frac{1}{h_{\mathrm{e}}}+\frac{1}{h_{\mathrm{i}}}$.

where $h_{\mathrm{e}}$ and $h_{\mathrm{i}}$ are the convection coefficients characterising the outer and inner thermal boundary layers of the wall.

Let $T_{0}$ be the temperature measured at $t=0 \mathrm{~s}$. The resolution of Eq. (10) yields:

$T=T_{0}+\left(T_{\mathrm{a}}+\frac{P}{k S}-T_{0}\right)\left[1-\exp \left(-\frac{t}{\tau}\right)\right]$,

with $\tau=m C / k S$.

In the case of wall made of $N$ layers, the computation is the same as previously, but more complicated. Let $\rho_{n}$ be the density of the layer $(n), e_{n}$, its thickness, $C_{n}$, its heat capacity and $R_{n}$, its thermal resistance. Neglecting the contact resistance between to successive layers, the time constant of the multilayer wall is found to be

$\tau=\frac{1}{k} \sum_{n=1}^{N} \rho_{n} e_{n} C_{n}$

with

$\frac{1}{k}=\frac{1}{h_{\mathrm{e}}}+\frac{1}{h_{\mathrm{i}}}+\sum_{n=1}^{N} R_{n} \quad$ and $\quad R_{n}=e_{n} / \lambda_{n}$. 


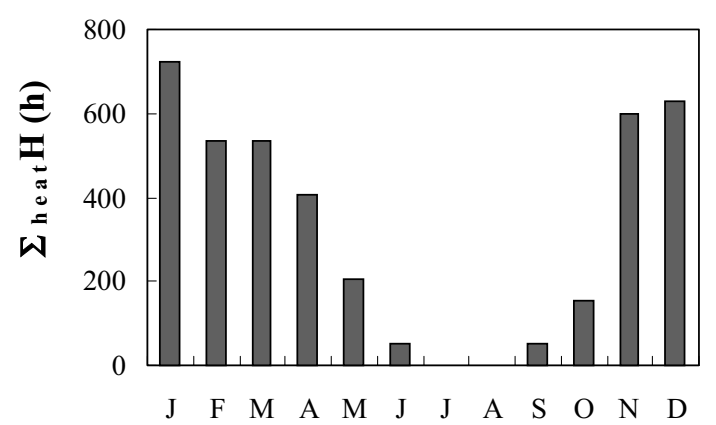

(a)

mon t h

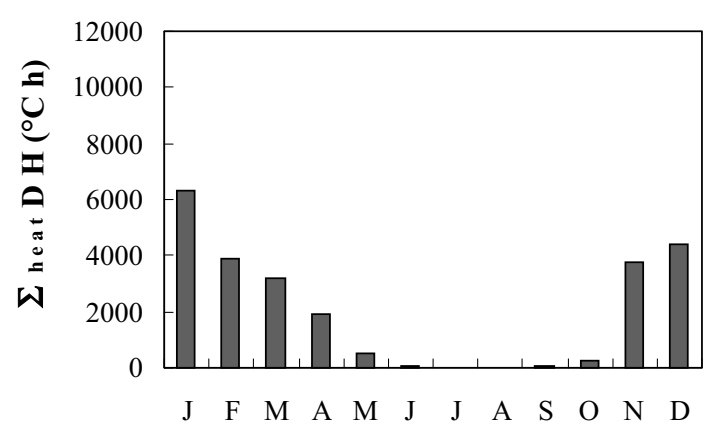

(b)

mo n t h

Fig. 5. (a) Number of hours of heating $\left(\sum_{\text {heat }} H\right)$ and (b) Number of degree hour of heating with respect to $18^{\circ} \mathrm{C}\left(\sum_{\text {heat }} \mathrm{DH}\right)$ in Oued Tlilat $($ Oran $)$.

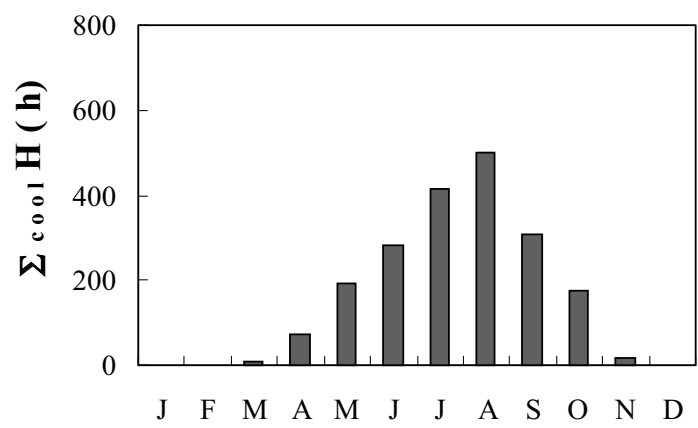

(a)

m o n t h

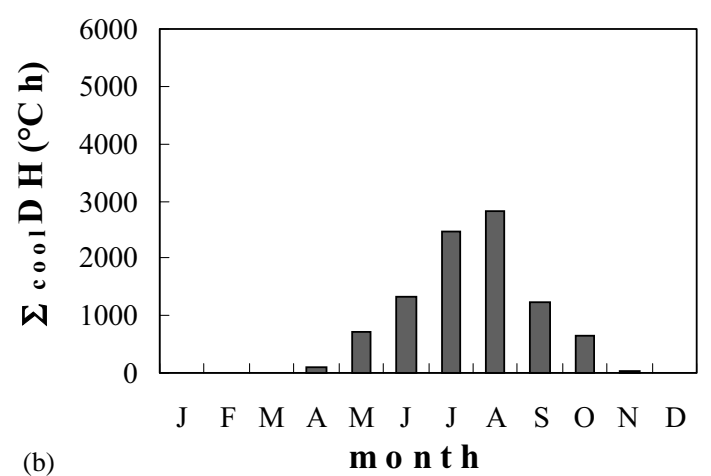

Fig. 6. (a) Number of hours of cooling $\left(\sum_{\text {cool }} H\right)$ and (b) Number of degree hour of cooling with respect to $25^{\circ} \mathrm{C}\left(\sum_{\text {cool }} \mathrm{DH}\right)$ in Oued Tlilat $($ Oran $)$.

Table 1 gives the technical characteristics of the thermal insulation materials currently used in the region of Djelfa. Five types of walls are then considered, which are:

- A: Double wall made of hollow bricks separated by an air layer $\left(e_{n}=10 \mathrm{~cm}\right.$ for each brick wall and $e_{n}=5 \mathrm{~cm}$ for the air layer. $C=0.34 \mathrm{Wh} / \mathrm{m}^{3}{ }^{\circ} \mathrm{C}$ and $R_{n}=0.16 \mathrm{~m}^{2}{ }^{\circ} \mathrm{C} / \mathrm{W}$ for air)

- B: Double wall made of hollow bricks separated by polystyrene $\left(e_{n}=10 \mathrm{~cm}\right.$ for each brick wall and $e_{n}=2 \mathrm{~cm}$ for the polystyrene layer).

- C: Blue stone with mortar $(e=30 \mathrm{~cm})$

- D: Mixture of clay and straw dried by sun $(e=40 \mathrm{~cm})$

- E: Double wall with polystyrene and plaster $\left(e_{n}=10 \mathrm{~cm}\right.$ for each brick wall, $e_{n}=2 \mathrm{~cm}$ for the polystyrene layer and $e_{n}=7 \mathrm{~cm}$ for the plaster layer)

Taking into account that $\left(1 / h_{\mathrm{e}}\right)+\left(1 / h_{\mathrm{i}}\right)=0.17 \mathrm{~m}^{2}{ }^{\circ} \mathrm{C} / \mathrm{W}$, the time constant $(\tau)$ has been computed for each of the five types of wall. The obtained values are listed in Table 2 following their increasing order. The process of thermal transfer described above, is very slow since it lasts several tens of hours before reaching its final state. This means that a room constructed with such walls, is insensitive to the quick variations of the external temperature and these walls are very good thermal insulators. In particular, the best thermal insulation is obtained when using the E-type of walls.

\section{Cost of insulation}

Let us consider the case of a house situated in Benahar and equipped with an air-conditioning installation. The total cost of each type of thermal insulation and the energy invoice have been evaluated knowing the cost of building surfaces, the gain in energy, the needs of cooling, and the cost of energy consumed by the air-conditioning installation. The experimental values of temperature gradient characterising each type of insulation and the building costs were provided by the Bureau of Technical Studies (B.E.T.) of Medea, which often works in the semi-arid regions of Algeria.

According to the experimentation, air will be renewed in a room by air-conditioning at a mean rate of $10 \mathrm{~m}^{3} / \mathrm{h}$. Since the specific heat of air equals $0.34 \mathrm{~W} \mathrm{~m}^{-3} /{ }^{\circ} \mathrm{C}$, the heat amount to be removed per hour, is: $Q=10 \times 0.34 \mathrm{Wh} /{ }^{\circ} \mathrm{C}=$ $3.4 \mathrm{Wh} /{ }^{\circ} \mathrm{C}$. As explained in the beginning of Section 4 , the number of degree hour necessary to cool a house in the region of Djelfa, is: $\mathrm{DH}_{\text {cool }}=14,833^{\circ} \mathrm{C} \mathrm{h}$, which must be provided over $2283 \mathrm{~h}$ of the year. The calculation of the corresponding energy losses yields: $Q \times \mathrm{DH}_{\text {cool }}=50,432 \mathrm{Wh}$. 

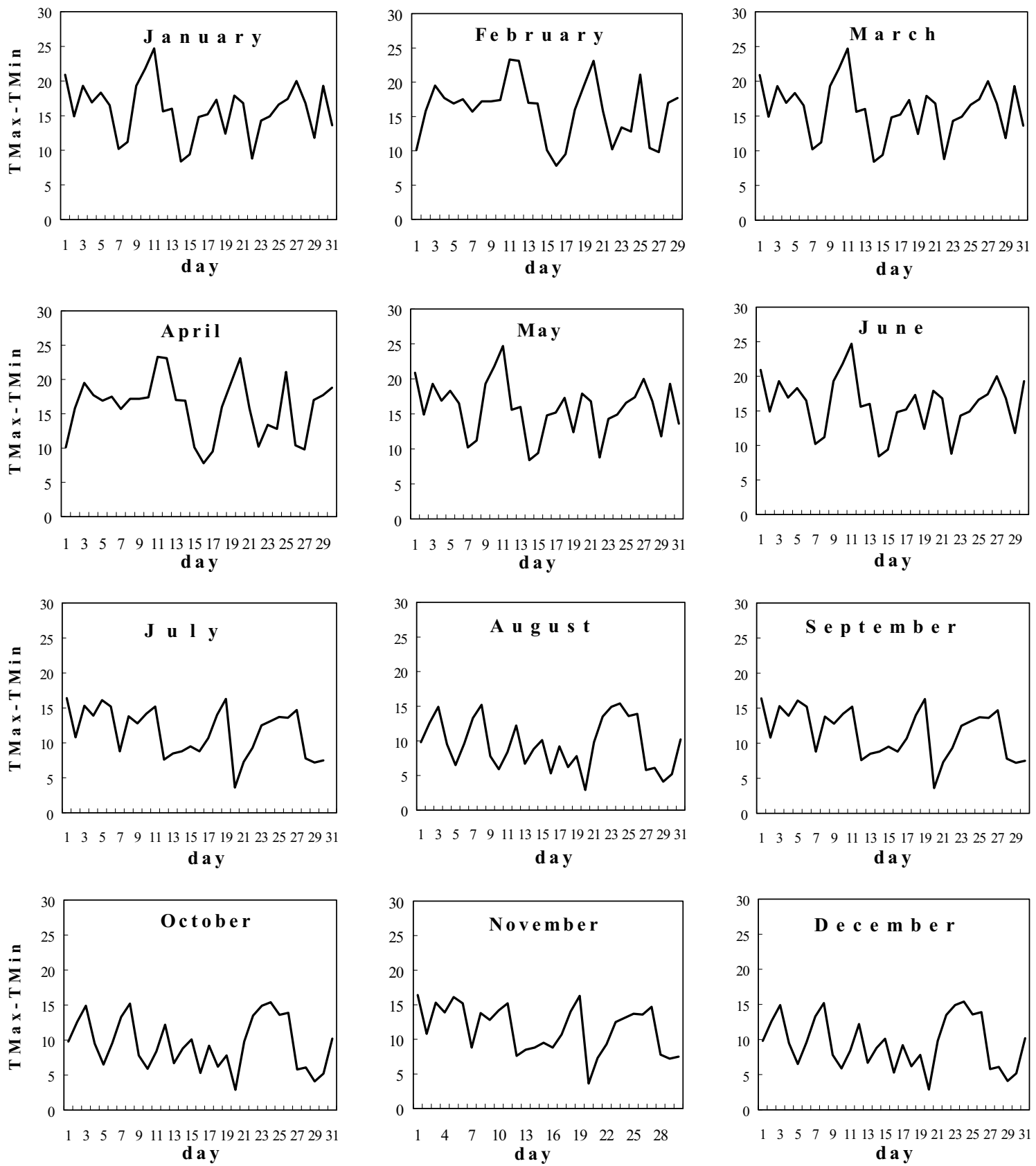

Fig. 7. Daily thermal deviations $\left({ }^{\circ} \mathrm{C}\right)$ observed at Oued Tlilat (Oran) from January to December. $\left(T_{\text {Max }}=\right.$ maximum daily temperature, $T_{\text {Min }}=$ minimum daily temperature).

Table 3 gives the numerical values of the thermal deviation $(\delta \tau)$ characterising the thermal inertia of each type of insulation. The energy amount stopped by a given type of insulation is $\Delta E=2283 \delta \tau$. The energy amount to be removed by air-conditioning over the year, is then equal to: $\Delta W=50,432-2283 \delta \tau$. In Table $3, \Delta W$ has been computed for the A, B, C, D, and E types of insulation. This table also gives the energy cost $\left(C_{\mathrm{W}}\right)$, the cost of constructed surface $\left(C_{\mathrm{S}}\right)$ and the total cost of insulation $\left(C_{\mathrm{T}}\right)$. The plot of Fig. 9 represents the cost of thermal insulation against the type of insulation. Following this diagram, the dried clay and straw mixture is the cheapest and most efficient thermal insulator. However, an opinion poll carried out by the B.E.T. in the region of Djelfa, shows that the population of this region no longer accepts to live in houses made of dried clay and straw mixture, because of their rusticity and ugliness. Stone is also a good thermal insulator. But, hewing and transport make this material expensive. The dried clay and straw 


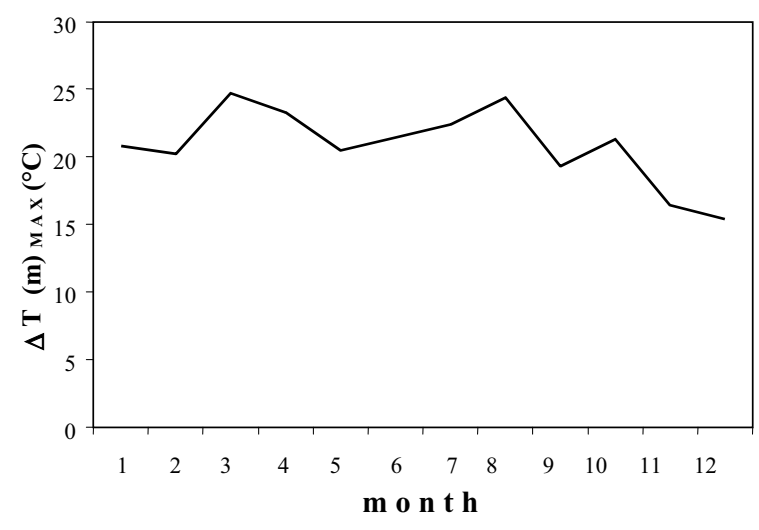

Fig. 8. The maximum amplitude of the monthly thermal deviation, $\Delta T(m)_{\text {Max }}=\operatorname{Max}\left(T_{\operatorname{Max}}(h, d)-T_{\text {Min }}(h, d)\right)$, observed in Oued Tlilat (Oran).

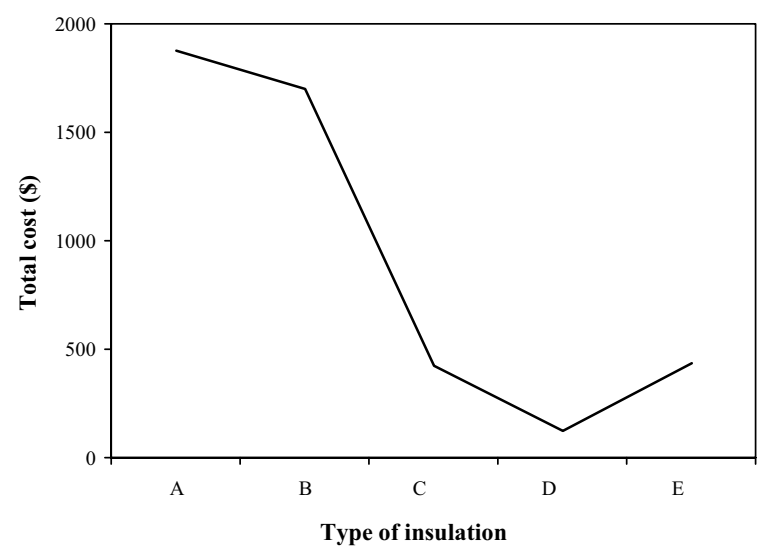

Fig. 9. Total cost of the different type of insulation under consideration (the cost has been calculated from the local money, by assuming that $1 \$=80$ Algerian Dinars).

Table 1

Density $(\rho)$, thermal conductivity $(\lambda)$ and specific heat $(C)$ of various construction materials

\begin{tabular}{lclc}
\hline Material & $\rho\left(\mathrm{kgr} / \mathrm{m}^{3}\right)$ & $\lambda\left(\mathrm{W} / \mathrm{m}^{\circ} \mathrm{C}\right)$ & $\mathrm{C}\left(\mathrm{J} / \mathrm{kg}{ }^{\circ} \mathrm{C}\right)$ \\
\hline Bricks & 1400 & 0.6 & 936 \\
Polystyrene & 20 & 0.04 & 1404 \\
Stone with mortar & 2200 & 1.4 & 1008 \\
Dried straw and clay & 1800 & 1.15 & 936 \\
Plaster & 1100 & 0.4 & 936 \\
\hline
\end{tabular}

mixture can be produced easily in the location under consideration and it requires no armature for the construction [23]. However, further investigations have to be made to improve the aspect of this material while keeping its thermal features unchanged.
Table 2

Thermal resistance $\frac{1}{h_{\mathrm{e}}}+\frac{1}{h_{\mathrm{i}}}+\sum_{i} R_{i}$ and time constant $(\tau)$ for five types of wall

\begin{tabular}{|c|c|c|}
\hline Type of insulation & $\begin{array}{l}\frac{1}{h_{\mathrm{e}}}+\frac{1}{h_{\mathrm{i}}}+\sum_{i} R_{i} \\
\left(\mathrm{~m}^{2}{ }^{\circ} \mathrm{C} / \mathrm{W}\right)\end{array}$ & $\tau$ (hours) \\
\hline A. Double wall (bricks + air) & 0.66 & 48 \\
\hline $\begin{array}{l}\text { B. Double wall (bricks+ } \\
\text { polystyrene) }\end{array}$ & 0.94 & 68 \\
\hline C. Blue stone & 0.38 & 71 \\
\hline D. Dried straw and clay & 0.52 & 97 \\
\hline $\begin{array}{l}\text { E. Double wall (bricks+ } \\
\text { plaster }+ \text { polystyrene) }\end{array}$ & 1.11 & 103 \\
\hline
\end{tabular}

Table 3

Cost of thermal insulation against the type of construction material when using air-conditioning to cool habitations in Benahar $(\delta \tau=$ thermal deviation characterising the insulation, $\Delta W=$ energy removed by air-conditioning $=50432-2283 \delta \tau . C_{\mathrm{W}}=$ energy cost, $C_{\mathrm{S}}=$ cost of constructed surface, $C_{\mathrm{T}}=$ total cost. $C_{\mathrm{W}}, C_{\mathrm{S}}$ and $C_{\mathrm{S}}$ have been calculated assuming that $1 \$=80$ Algerian Dinars)

\begin{tabular}{llllll}
\hline $\begin{array}{l}\text { Type of } \\
\text { insulation }\end{array}$ & $\begin{array}{l}\delta \tau \\
\left({ }^{\circ} \mathrm{C}\right)\end{array}$ & $\begin{array}{l}\Delta W \\
(\mathrm{Wh})\end{array}$ & $\begin{array}{l}C_{\mathrm{W}} \\
(\$)\end{array}$ & $\begin{array}{l}C_{\mathrm{S}} \\
\left(\$ / \mathrm{m}^{2}\right)\end{array}$ & $\begin{array}{l}C_{\mathrm{T}} \\
(\$)\end{array}$ \\
\hline $\begin{array}{l}\text { A. Double wall } \\
\quad \text { (bricks + air) }\end{array}$ & 0.1 & 48,103 & 1726 & 150 & 1876 \\
$\begin{array}{l}\text { B. Double wall } \\
\quad \text { (bricks + polystyrene) }\end{array}$ & 1 & 42,670 & 1500 & 200 & 1700 \\
$\begin{array}{l}\text { C. Blue stone } \\
\begin{array}{l}\text { D. Dried straw and clay } \\
\text { E. Double wall }\end{array}\end{array}$ & 5 & 11,621 & 223 & 200 & 423 \\
$\quad 7$ & 0 & 0 & 125 & 125 \\
$\quad$ plaster + polystyrene) & & 0 & 0 & 438 & 438 \\
\hline
\end{tabular}

\section{Conclusion}

The approach presented above, enables the evaluation of the effect of temperature variations at two locations in Algeria, namely Benahar and Oued Tlilat, which lie in semi-arid and temperate regions, respectively. It shows that the temperature variations in Benahar are very different from those observed in Oued Tlilat, and that heating exchanges at the earth surface vary significantly in semi-arid regions over the year. To improve the living conditions of the populations, these variations must be taken into account in the building of housing in semi-arid regions. However, as explained in Section 4, it is not sufficient to evaluate the yearly thermal extreme when designing such dwellings, but the duration and number of degree hour of cooling and heating totalled over the year must also be considered. Thanks to this kind of calculation, the thermal insulation of constructions in semi-arid regions and their architecture can be suitably managed and the size of heating and air-conditioning installations can be optimised.

More generally, such an approach is directly applicable to the development of industrial and agricultural projects. It could be extended to the other locations lying in the semi-arid part of Algeria. However, hourly temperature data are recorded in only few locations of such a region. Then, it 
could be useful to simulate such data in any site of southern Algeria and build a cartography of degree hour and duration characterising the heating and cooling for this region.

In the present study, only the effect of temperature on housing has been considered. However, other meteorological phenomena, such as humidity or wind, also influence the comfort of populations. It is then of great interest to analyse these parameters and use them so as to improve the living conditions in semi-arid regions. For example, the location and orientation of the dwellings in these regions could be correctly chosen if wind speed and direction were known. Moreover, damp air blowers could be advantageously used to increase the humidity rate and improve natural cooling in these houses [24-27].

\section{Acknowledgements}

We wish to specially thank Mr Mohamed Kadi, Director of the Climatology Centre of Dar El Beida (National Office of Meteorology), Mr Lamri Nacef, Technical Manager of this Centre, for having provided us with the meteorological data necessary to this study, and Mr Mohamed Benzaid, Director of the Bureau of Technical Studies of Medea, for having efficiently documented us about the technical features and the cost of construction materials used in the semi-arid regions.

\section{References}

[1] Dubief J. Alizés, harmattan et vents de sables étésiens. Alger: Inst Rech Sah. 1951;TVII:187-9.

[2] Sayigh AAM. Introduction. Renewable and Sustainable Energy Reviews 1998;2(1-2):1-2.

[3] Sayigh AAM, Marafia AH. Thermal comfort and the development of bioclimatic concept in building design. Renewable and Sustainable Energy Reviews 1998;2(1-2):3-24.

[4] Butera FM. Principles of thermal comfort. Renewable and Sustainable Energy Reviews 1998;2(1-2):39-87.

[5] Eckholm EP. Losing ground. Environment stress and world food. Prospects. New York: WW Norton. 1976. 47pp.

[6] Serra R. Daylighting. Renewable and Sustainable Energy Reviews 1998;2(1-2):115-55.

[7] Gallo C. The utilization of microclimate elements. Renewable and Sustainable Energy Reviews 1998;2(1-2):89-114.

[8] Awbi HB. Ventilation. Renewable and Sustainable Energy Reviews 1998;2(1-2):157-88
[9] Coch H. Bioclimatism in vernacular architecture. Renewable and Sustainable Energy Reviews 1998;2(1-2):67-87.

[10] Muneer J, Abodahab N, Weir G, Kubie J. Windows in buildings: thermal, acoustic, visual and solar. Renewable and Sustainable Energy Reviews 2001;5(2):201-2.

[11] Douguedroit A. The variations of dry spells in Marseille from 1865 to 1984 . Journal of Climatology, Royal Meteorological Society 1987;7:541-51.

[12] Daget P, Djellouli Y. Le climat méditerranéen change-t-il? La sécheresse à Alger au cours des cent dernières années. Publ Assoc Intern Climat 1991;4:187-95.

[13] Algifri AH, Bin Gadhi SM, Nuaguna BT. Thermal behaviour of adobe and concrete houses in Yemen. Renewable Energy 1992;2(6):597-602.

[14] Bajwa MM. Direct convective passive cooling as an energy conserving technique in the maritime desert climate of the Arabian Gulf Region. Renewable Energy 1992;2(3):255-73.

[15] Sala M. Technology for modern architecture. Renewable and Sustainable Energy Reviews 1998;2(1-2):189-234.

[16] Dubief J. Les vents et le déplacement du sable au Sahara. Alger: Inst Rech Sah. 1952;TVIII:123-62.

[17] Bagnold RA. The physics of blown sand and desert dunes. Londres: Methuen, 1954. XXIV-226pp.

[18] UNCOD. Desertification: its causes and consequences. Secretariat of United Nations, Conference on desertification. Kenya, Nairobi: Pergamon Press, 1977.

[19] Sheridon D. Desertification of the United States. Council on Environmental Quality, 1981, 142pp.

[20] Baker R. Desertification and control. A study of the UN Plan of Action and its possible application. Sc. Rev Arid Zone Research. Jodhpur: Scientific Publishers. 1982. 285pp.

[21] Hellden U. Desertification monitoring: is the desert encroaching? Desertification control. Bulletin, vol. 17, Nairobi, Kenya, 1988. p. $8-11$.

[22] Warren A, Agnew C. An assessment of desertification and land degradation in arid and semi-arid areas. International Institute for Environment and Development. Drylands Programme. University College, London, 1988. 72pp.

[23] Legget J. A guide to the Kyoto Protocol: a treaty with potentially strategic implications for the renewable industry. Renewable and Sustainable Energy Reviews 1998;2(4):345-51.

[24] Edinger R, Kaul S. Human kind's detour toward sustainability: past, present and future of renewable energies and electric power generation. Renewable and Sustainable Energy Reviews 2000;4(3):295-313.

[25] Elkadi H. Ecological approach for the evaluation of intelligence energy features in a building's skin. Renewable and Sustainable Energy Reviews 2000;4(1):91-103.

[26] Li J. The bioclimatic features of vernacular architecture in China. Renewable Energy 1996;8(1-5):305-8.

[27] Sayigh AAM, Marafia AH. Vernacular and contemporary buildings in Quatar. Renewable and Sustainable Energy Reviews 1998;2(12):25-37. 